\title{
Effects of Salt Stress on Physiological Indexes of 'Ganmi 6' and 'Hayward' Kiwifruit Seedlings
}

\author{
Yunmei Wang ${ }^{1, a}$, Hui Xia ${ }^{1,2, b}$, Xiu Wang ${ }^{1, c}$, Yanqiu Shen ${ }^{1, d}$, Dong Liang ${ }^{1,2, e, *}$ \\ ${ }^{1}$ College of Horticulture, Sichuan Agricultural University, Chengdu, Sichuan, China \\ ${ }^{2}$ Institute of Pomology and Olericulture, Sichuan Agricultural University, Chengdu, Sichuan, China \\ a1336489390@qq.com, bsusanxia_2001@163.com, '347434587@qq.com, d517590097@qq.com, \\ eliangeast@sina.com
}

${ }^{*}$ Corresponding author. Yunmei Wang and Hui Xia contributed equally to this work.

Key words: Kiwifruit; Salt stress; Antioxidant system

Abstract: Seedlings of two kiwifruit varieties, 'Ganmi 6' and 'Hayward', were used as experimental materials to study their tolerance to salt stress by comparing physiological indexes , The results showed that the contents of $\mathrm{H}_{2} \mathrm{O}_{2}$, MDA, chlorophyll and soluble protein in leaves of seedlings increased with the salt concentrations increase, accompanied with increased membrane permeability. At the same time, the activities of POD and SOD gradually increased. Furthermore, Hayward had significant higher than the Hair flower, indicating its more sensitive to salt stress.

\section{Introduction}

The impact of soil salinization on modern agriculture has evolved into a global environmental issue [1]. At present, about 36.9 million $\mathrm{hm}^{2}$ of land in China are affected by salinization, and the area affected is getting larger [2]. As a highly soluble salt, $\mathrm{NaCl}$ is the most important factor causing soil salinization. Soil salinity inhibits plant growth and development, leading to a significant decrease in its yield [3]. Actinidia, belonging to Actinidiaceae class, Actinidia family, is an important fruit tree resource with high nutritional value and is favored by many people [4]. A large number of research experiments show that the salt tolerance of kiwifruit is not strong, neither tolerance nor impatience ion stress [5]. Therefore, selection and breeding materials with high salt tolerance is of great significance. In the study, we compared the salt tolerance of the two kiwifruit cultivars.

\section{Materials and Methods}

Plant Preparation and Treatment. 'Ganmi 6' belongs to Actinidia eriantha and Hayward belongs to Actinidia deliciosa. Seeds of Hair flower and 'Hayward' were picked in September 2016. The seeds were soaked in 5\% sodium hypochlorite solution for $5 \mathrm{~min}$ and then placed in a Petri dish containing $0.1 \%$ Captan solution and refrigerated at $4{ }^{\circ} \mathrm{C}$ for 2 months. After variable temperature treatment at $4 \square 16 \mathrm{~h}, 25 \pm 1 \square 8 \mathrm{~h}$ for 15 days, seeds was sown into a tray with a substrate and cultured in a climatic chamber at $(25 \pm 2) \square$ with a light-dark period of $12 \mathrm{~h} / 12 \mathrm{~h}$.

When grown up to 7-8 leaves, uniform and strong seedlings of each variety were selected and divided into 4 parts equally, and transfer to the hydroponic box $(40 \mathrm{~cm} \times 35 \mathrm{~cm} \times 15 \mathrm{~cm})$ for water planting with $1 / 2$ Hogland solution. Solution was changed every 3 days. After 5 days cultivation for adaptation, $\mathrm{NaCl}$ was added to cultivation solution as below: $0(\mathrm{CK}), 50,100$ and $150 \mu \mathrm{mol} \cdot \mathrm{L}^{-1}$ of respectively. Each treatment contained 12 plants with three replicates. Treatment lasted for 4 days. 
Leaf samples were harvested on 4th day. The leaves were snap-frozen in liquid nitrogen and stored at $-80 \square$ in a refrigerator.

Determination of physiological index. $\mathrm{H}_{2} \mathrm{O}_{2}$ content determination method adopts Lin Zhi-fang [6]. Relative electric conductivity, MDA and antioxidant enzymes (SOD, POD) content determination method adopted Li Hesheng [7]. The content of chlorophyll was determined by the modified method of Gao Junfeng and soluble protein content determination of the coomassie brilliant blue G-250 staining method [8,9].

Data Analysis. Analysis of variance was performed using the SPSS 20.0 software. Each treatment was replicated three times. Significant differences were detected using Duncan's test at the $\mathrm{P}<0.05$ level.

\section{Results and Discussion}

$\mathrm{H}_{2} \mathrm{O}_{2}$, MDA Content and Relative Electrical Conductivity. When treated with $\mathrm{NaCl}, \mathrm{H}_{2} \mathrm{O}_{2}$ content in leaves of two varieties had no significant difference with control when $\mathrm{NaCl}$ concentration below $100 \mathrm{mmol} \cdot \mathrm{L}^{-1}$, but increased significant when $\mathrm{NaCl}$ concentration reached to $150 \mathrm{mmol} \cdot \mathrm{L}^{-1}$, indicating $150 \mathrm{mmol} \cdot \mathrm{L}^{-1} \mathrm{NaCl}$ induced salt stress on kiwifruit seedling. Furthermore, two varieties showed distinct different response to salt stress $\left(150 \mathrm{mmol} \cdot \mathrm{L}^{-1} \mathrm{NaCl}\right), \mathrm{H}_{2} \mathrm{O}_{2}$ content in 'Hayward' peaked to $273.91 \mathrm{mmol} \cdot \mathrm{g}^{-1}$, which was almost double of that of in 'Ganmi 6', indicating 'Hayward' was more sensitive to salt stress than Hair Flower (figure. 1A).

In 'Ganmi 6', MDA content in leaves was increased significantly with the increasing of $\mathrm{NaCl}$ concentration, but there was no significant difference between 100 and $150 \mathrm{mmol} \cdot \mathrm{L}^{-1} \mathrm{NaCl}$. In 'Hayward', MDA content at $0 \mathrm{mmol} \cdot \mathrm{L}^{-1} \mathrm{NaCl}$ was apparent higher than that in 'Ganmi 6', but there was no significant increase when $\mathrm{NaCl}$ concentration increased to $50 \mathrm{mmol} \cdot \mathrm{L}^{-1}$. Afterwards, with the adding of $\mathrm{NaCl}$, MDA content in 'Hayward' increased rapidly, and peaked at $150 \mathrm{mmol} \cdot \mathrm{L}^{-1}$ with $15.13 \mu \mathrm{mol} \cdot \mathrm{g}^{-1} \mathrm{FW}$. Under the same salt concentration, the MDA content of 'Hayward' kiwifruit was always higher than that of 'Ganmi 6' (figure. 1B).

The relative electric conductivity (REC) of the two varieties both showed an upward trend with the increasing of $\mathrm{NaCl}$ concentration. REC of the 'Ganmi 6' was always lower than that of the 'Hayward' under different salt concentrations. Both kiwifruit cultivars peaked at the salt stress of $150 \mathrm{mmol} \cdot \mathrm{L}^{-1}$, but the maximum conductivity of the salt concentration, the MDA content of 'Hayward' kiwifruit was always higher than that of 'Ganmi 6' varieties was $47.61 \%$, far lower than $93.66 \%$ of the 'Hayward' (figure. 1C).
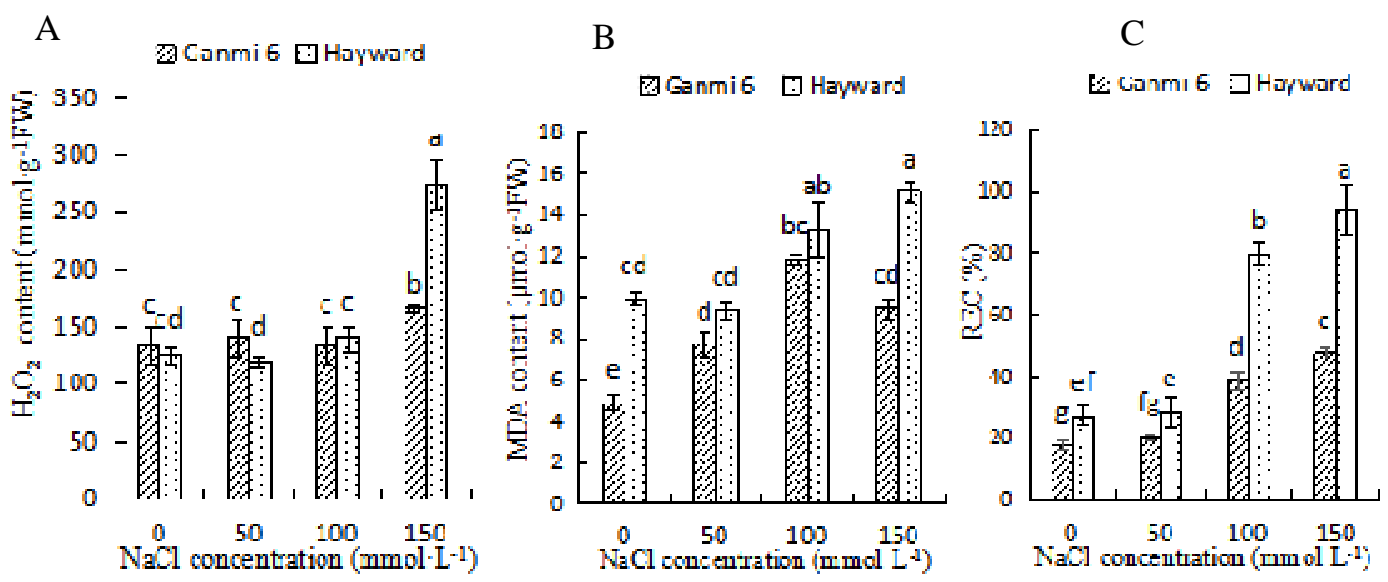

Figure. $1 \mathrm{H}_{2} \mathrm{O}_{2}(\mathrm{~A})$, MDA content (B) and $\mathrm{REC}(\mathrm{C})$ in two kiwifruit varieties under salt treatments 
Chlorophyll Content and Soluble Protein Content. The chlorophyll content reached the highest under the $\mathrm{NaCl}$ stress of $50 \mathrm{mmol} \cdot \mathrm{L}^{-1}$. With the increasing of $\mathrm{NaCl}$ concentration, the chlorophyll content in leaves of 'Hayward' decreased firstly and then increased. The chlorophyll content was decreased after the $\mathrm{NaCl}$ concentration was $100 \mathrm{mmol} \cdot \mathrm{L}^{-1}$. Under the stress of 50 $\mathrm{mmol} \cdot \mathrm{L}^{-1} \mathrm{NaCl}$, there was no significant change in the chlorophyll content. Under the same salt stress, the chlorophyll content in 'Hayward' kiwifruit seedlings was significantly higher than that in salt concentration, the MDA content of 'Hayward' kiwifruit was always higher than that of 'Ganmi 6' varieties and the differences were significant at the concentration of $100 \mathrm{mmol} \cdot \mathrm{L}^{-1}$ and 150 $\mathrm{mmol} \cdot \mathrm{L}^{-1}$, which increased by $63.64 \%, 72.22 \%$ respectively(figure. $2 \mathrm{~A}$ ). The soluble protein content in the 'Ganmi 6' kiwifruit did not vary greatly with the increasing of $\mathrm{NaCl}$ concentration, fluctuating between 5 and $6 \mathrm{mg} \cdot \mathrm{g}^{-1}$. The soluble proteins content under $100 \mathrm{mmol} \cdot \mathrm{L}^{-1}$ and 150 mmol $\cdot \mathrm{L}^{-1} \mathrm{NaCl}$ stress were basically unchanged. There was no significant difference in the soluble protein content between the seedlings treated with $50 \mathrm{mmol} \cdot \mathrm{L}^{-1} \mathrm{NaCl}$ and control treatment. The soluble protein content in the 'Hayward' kiwifruit increased gradually, reaching the highest at 100 $\mathrm{mmol} \cdot \mathrm{L}^{-1}$, and then decreased. The maximum content reached $6.39 \mathrm{mg} \cdot \mathrm{g}^{-1}$ (Figure. $2 \mathrm{~B}$ ).
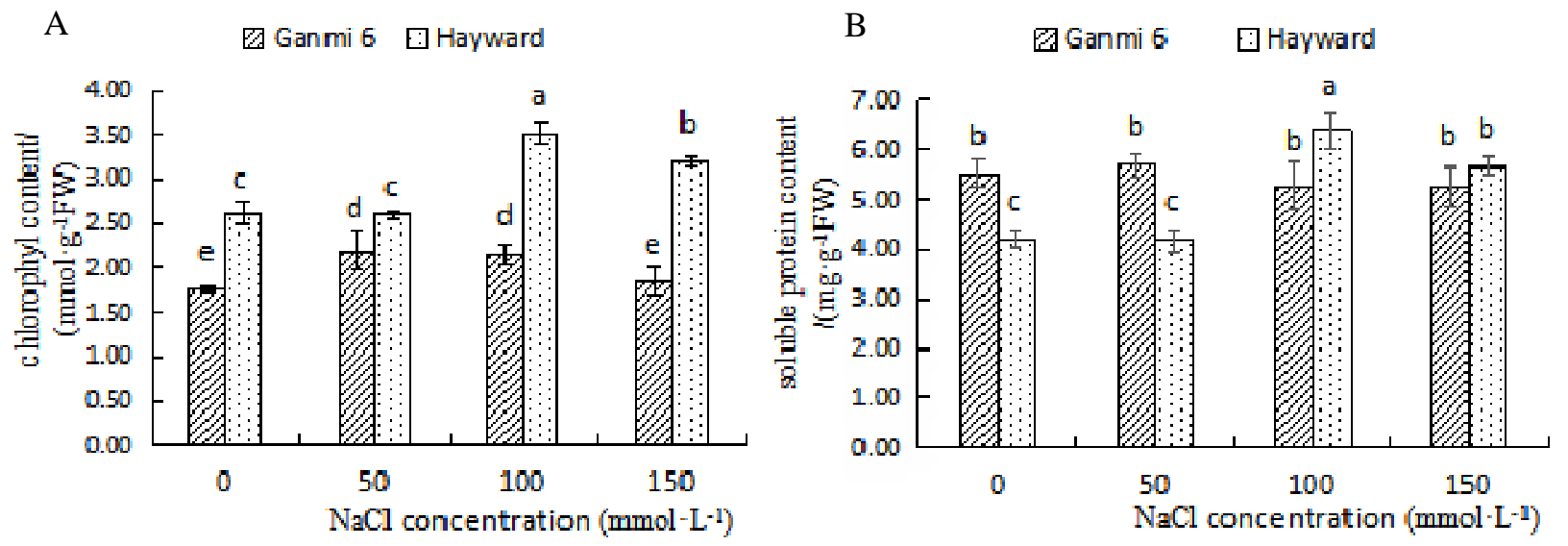

Figure.2 Chlorophyll contents (A) and soluble protein content (B) treatment in two kiwifruit varieties under salt
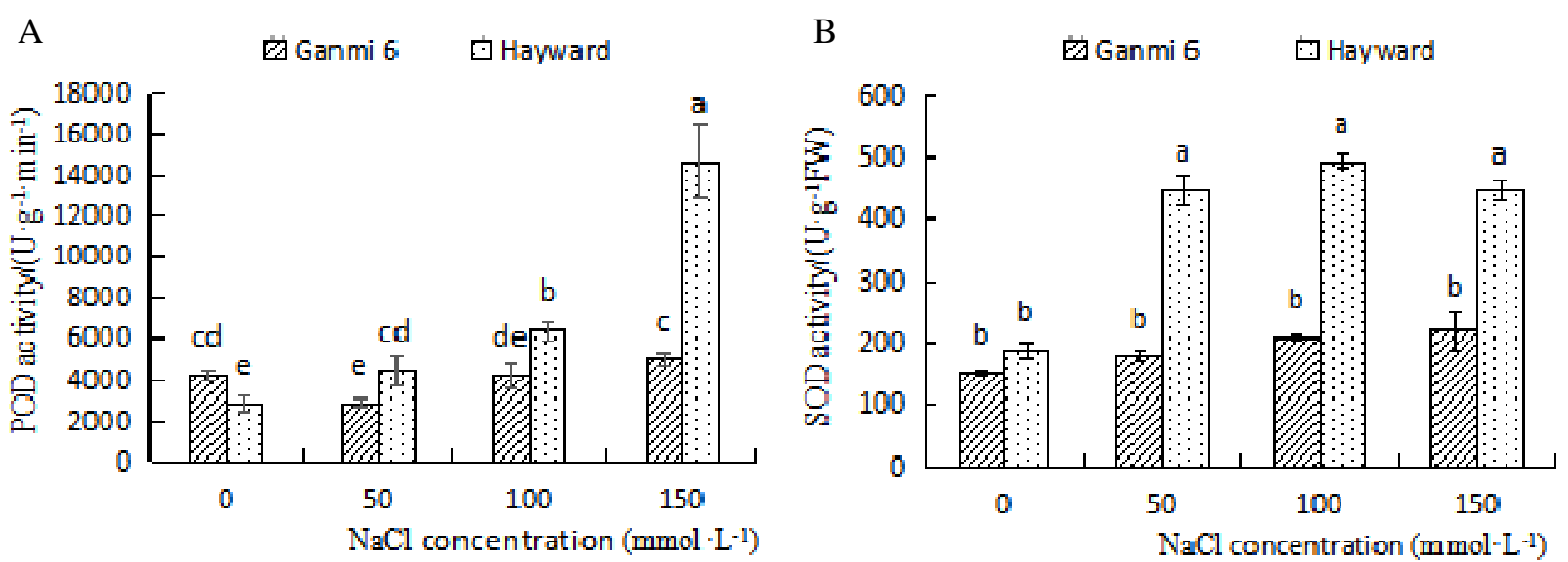

Figure.3 POD (A) and SOD Activity (B) in two kiwifruit varieties under salt

POD Activity and SOD Activity. When $\mathrm{NaCl}$ concentration was $50 \mathrm{mmol} \cdot \mathrm{L}^{-1}$, POD activity of the 'Ganmi 6' kiwifruit was slightly lower than that of control treatment, and then increased. POD 
activity of 'Hayward' cultivars always increased with the increasing of $\mathrm{NaCl}$ concentration, and POD activity at $150 \mathrm{mmol} \cdot \mathrm{L}^{-1} \mathrm{NaCl}$ stress was significantly higher than that under low salt stress (Figure. 3A). SOD activity of 'Hayward' increased significantly at $\mathrm{NaCl}$ concentration of 0-50 $\mathrm{mmol} \cdot \mathrm{L}^{-1}$, reaching the maximum at $100 \mathrm{mmol} \cdot \mathrm{L}^{-1}$. SOD activities of two varieties of 'Ganmi 6' and 'Hayward' kiwifruit seedlings generally showed an upward trend as the increasing of $\mathrm{NaCl}$ concentration, which were higher than the control. SOD activity of 'Hayward' seedlings was significantly higher than that of 'Ganmi 6' under the same salt stress (Figure. 3B).

\section{Conclusions}

The results of experiments showed that salt stress can inhibit the growth of kiwifruit seedlings and destroy the antioxidant system. The physiological indexes of 'Ganmi 6' and 'Hayward' kiwifruit seedlings were affected to varying degrees with the increasing of $\mathrm{NaCl}$ concentration. Overall, the higher the $\mathrm{NaCl}$ concentration, the more severe the salt stress. The content of $\mathrm{MDA}, \mathrm{H}_{2} \mathrm{O}_{2}$, chlorophyll and soluble protein in leaves of two kiwifruit cultivrs increased under different concentrations of salt stress, relative conductivity was also. At the same time, the activities of POD and SOD in leaves were also increased. High-salt stress inhibited the growth of 'Ganmi 6' and 'Hayward' kiwifruit, and the salt tolerance of 'Ganmi 6' kiwifruit was significantly higher than that of 'Hayward'.

\section{References}

[1] D.M. Chen, J.S. Yang: Advance in Soil Science (1995), p. 23. ( in Chinese)

[2] X. Zhao, J.C. Ha and H.Y. Wang, in: Chinese Agricultural Science Bulletin. Research progress ofsaline soil improvement technology (2016), p. 32. (in Chinese with English abstract)

[3] H. Evelin, R. Kapoor and B. Giri: Arbuscular mycorrhizal fungi in alleviation of salt stress (2009). p. 104

[4] H.W. Huang: Research progress of kiwifrui. Science Press (2000). ( in Chinese)

[5] K. Ma, L.J. Wang and Y.L. Wang: Study on salt resist-ance and salt tolerance of 18 kinds of fruit trees. Journal of Fruit Science (1997), p. 14. ( in Chinese)

[6] Z.F. Lin, S.S. Li and G.Z. Lin: Journal of Plant Physiology (1988), p. 24. (in Chinese)

[7] H.S. Li: Principle and technology of plant physiology and biochemistry experient (2000). (in Chinese)

[8] J.F. Gao: Plant Physiology Experiment Guide (2006). ( in Chinese)

[9] J. Li, T. Yao and W. Zeng: Determination of total protein content by Coomassie brilliant blue method (2000). 